Required software to e-Annotate PDFs: Adobe Acrobat Professional or Adobe Reader (version 11 or above). (Note that this document uses screenshots from Adobe Reader DC.)

The latest version of Acrobat Reader can be downloaded for free at: http://get.adobe.com/reader/

Once you have Acrobat Reader open on your computer, click on the Comment tab (right-hand panel or under the Tools menu).

This will open up a ribbon panel at the top of the document. Using a tool will place a comment in the right-hand panel. The tools you will use for annotating your proof are shown below:

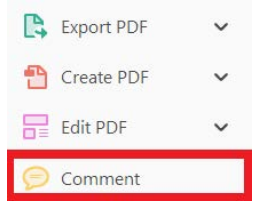

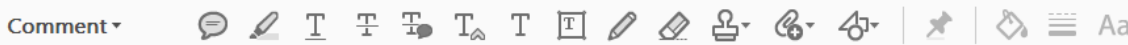

1. Replace (Ins) Tool - for replacing text.

T. Strikes a line through text and opens up a text box where replacement text can be entered.

How to use it:

- Highlight a word or sentence.

- Click on $T_{D}$.

- Type the replacement text into the blue box that appears.

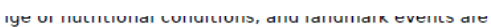
nitored in populations of relatively homogeneous single $\mathrm{n}$ of

and Is initiated atter

carbon source [ 1]. S

are referred to as mei

rof meiosis-specific

inducer of meiosis) [3

I

1 functions as a repre

repression, the genes

pression) and RGRI a।

rase II mediator subur

irectly or indirectly re

Post jstaddon.

Reply $x$

Reply $X$

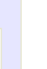


5. Attach File Tool - for inserting large amounts of text or replacement figures.

Inserts an icon linking to the attached file in the Q appropriate place in the text.

How to use it:

- Click on $\&^{\text {- }}$

- Click on the proof to where you'd like the attached file to be linked.

- Select the file to be attached from your computer or network.

- Select the colour and type of icon that will appear in the proof. Click OK.

The attachment appears in the right-hand panel.

:hondrial nreparatior ative da ie extent of membra I, malondialdehyde ( (TBARS) formation.' inad bu biak marfam
6. Add stamp Tool - for approving a proof if no corrections are required.

$\Omega$ Inserts a selected stamp onto an appropriate place in the proof.

How to use it:

- Click on $\Omega$.

- Select the stamp you want to use. (The Approved stamp is usually available directly in the menu that appears. Others are shown under Dynamic, Sign Here, Standard Business).

- Fill in any details and then click on the proof where you'd like the stamp to appear. (Where a proof is to be approved as it is, this would normally be on the first page).

)t the Dusiness cycie, starting with the on perfect competition, constant ret

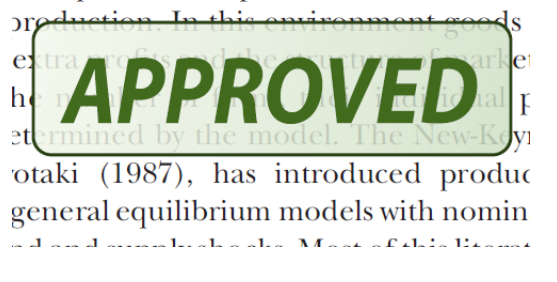

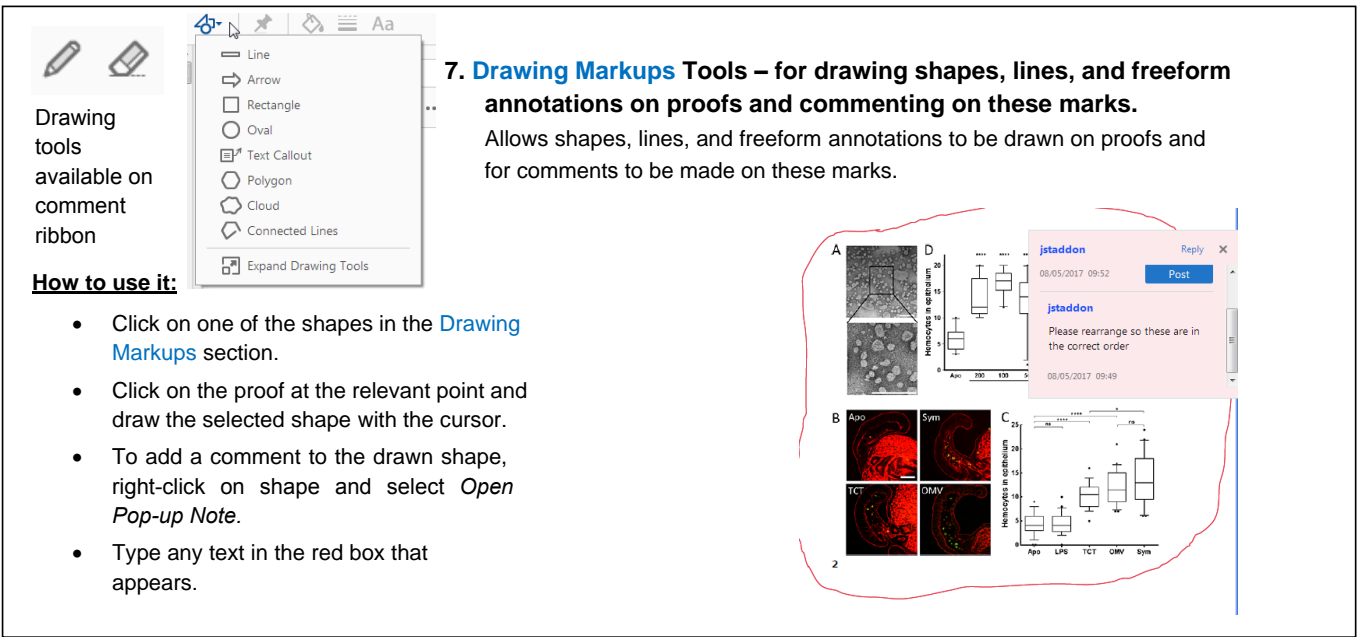

For further information on how to annotate proofs, click on the Help menu to reveal a list of further options:

Welcome...

?) Learn Adobe Acrobat Reader DC..

About Adobe Acrobat Reader DC...

About Adobe Plug-Ins...

Generate System Report...

Repair Installation

Check for Updates... 


\section{Author Query Form}

\section{Journal: PPA}

\section{Article: 13092}

Dear Author,

During the copyediting of your manuscript the following queries arose.

Please refer to the query reference callout numbers in the page proofs and respond to each by marking the necessary comments using the PDF annotation tools.

Please remember illegible or unclear comments and corrections may delay publication.

Many thanks for your assistance.

AUTHOR: Please note that missing content in references have been updated where we have been able to match the missing elements without ambiguity against a standard citation database, to meet the reference style requirements of the journal. It is your responsibility to check and ensure that all listed references are complete and accurate.

\begin{tabular}{|l|l|l|}
\hline Query reference & Query & Remarks \\
\hline 1 & $\begin{array}{l}\text { AUTHOR: Please read through the entire proof carefully, paying particular attention to } \\
\text { the accuracy of equations, tables, illustrations (which may have been redrawn), other } \\
\text { numerical matter and references (which have been corrected for style but not checked } \\
\text { for accuracy, which remains the responsibility of the author). }\end{array}$ & $\begin{array}{l}\text { AUTHOR: Please note that the version of your paper that appears online is complete } \\
\text { and final, except for volume, issue and page numbers, which are added upon print } \\
\text { publication. Therefore, there will be no further opportunity to make changes to your } \\
\text { article after online publication. }\end{array}$ \\
\hline 2 & $\begin{array}{l}\text { AUTHOR: Please confirm that given names (blue) and surnames/family names } \\
\text { (vermilion) have been identified correctly. }\end{array}$ & \\
\hline 3 & AUTHOR: Please verify that the linked ORCID identifiers are correct for each author. & \\
\hline
\end{tabular}




\section{Funding Info Query Form}

Please confirm that the funding sponsor list below was correctly extracted from your article: that it includes all funders and that the text has been matched to the correct FundRef Registry organization names. If a name was not found in the FundRef registry, it may not be the canonical name form, it may be a program name rather than an organization name, or it may be an organization not yet included in FundRef Registry. If you know of another name form or a parent organization name for a "not found" item on this list below, please share that information.

\begin{tabular}{|l|l|}
\hline FundRef name & FundRef Organization Name \\
\hline MINECO & Ministerio de Economía y Competitividad \\
\hline FEDER & Federación Española de Enfermedades Raras \\
\hline CONACYT & Consejo Nacional de Ciencia y Tecnología \\
\hline
\end{tabular}




\title{
Fitness cost but no selection for virulence in Meloidogyne incognita after two consecutive crops of eggplant grafted a d onto Solanum torvum
}

\author{
43 H. A. García-Mendívil(iD and F. J. Sorribas*
}

Department of Agri-Food Engineering and Biotechnology, Universitat Politècnica de Catalunya, Esteve Terradas 8, 08860 Castelldefels, Barcelona, Spain

\begin{abstract}
The eggplant Solanum melongena 'Cristal', either ungrafted or grafted onto the Solanum torvum 'Brutus' rootstock, was cultivated for two consecutive years in the same plots in a plastic greenhouse to assess the level of resistance to Meloidogyne incognita and crop yield. At the end of the second crop, the putative selection for virulence of the nematode subpopulations coming from infected ungrafted and grafted eggplant was assessed in the eggplant and in S. torvum in a pot experiment. Nematode population densities at transplantation in 2017 ranged from 2 to $378100 \mathrm{~cm}^{-3}$ of soil and did not differ between ungrafted and grafted eggplant. At the end of each crop, higher galling index and number of nematodes in soil and in roots were registered in ungrafted than grafted eggplant. The grafted eggplant was categorized as resistant in 2017 and as highly resistant in 2018. Eggplant yield did not differ irrespective of grafting in 2017 after being cultivated for 135 days, but did differed after 251 days of cultivation in 2018. In the pot experiment, S. torvum was categorized as resistant to both M. incognita subpopulations. However, the M. incognita subpopulation obtained from roots of S. torvum produced $49.4 \%$ fewer egg masses and $56 \%$ fewer eggs per plant in the eggplant than the nematode subpopulation obtained from roots of the eggplant cv. Cristal. The results of this study reveal that the infective and reproductive fitness of the nematode decreased without having been selected for virulence.
\end{abstract}

Keywords: eggplant yield, grafting, resistance durability, root-knot nematode, rootstock, Solanum melongena

\section{Introduction}

Eggplant, Solanum melongena, is one of the most cultivated solanaceous crops with an estimated worldwide production of $c$. 52 million tonnes in 1.8 million ha (FAOSTAT, 2017). Root-knot nematodes (RKN), Meloidogyne spp., are one of the most damaging soilborne pathogens in solanaceous crops, especially under protected cultivation (Hallman \& Meressa 2018). Maximum eggplant yield losses of $95 \%$ have been reported (Greco \& Di Vito, 2009). The use of resistant plants is an effective and economically profitable management strategy to control RKN (Sorribas et al., 2005) that is more environmentally friendly than the common soil nematicides (Nyczepir \& Thomas, 2009). In nematology, plant resistance is defined as the ability of a plant to suppress infection development and/or reproduction of plant-parasitic nematodes (Roberts, 2002). Grafting onto resistant rootstocks has become a common method to control soilborne pathogens when no commercial resistant cultivars are available (Lee \& Oda, 2002; Thies et al., 2015). That is the case for eggplant, which is

*E-mail: francesc.xavier.sorribas@upc.edu usually grafted onto resistant tomato or interspecific hybrids such as $S$. lycopersicum $\times S$. habrochaites (Daunay, 2008). However, the expression of resistance can be limited by several factors such as constant soil temperatures above $30{ }^{\circ} \mathrm{C}$ (Araujo et al., 1982), and the genetic background of the rootstock along with that of the nematode species (Cortada et al., 2008). Moreover, the repeated cultivation of plant species carrying the same resistance gene can select virulent nematode populations capable of overcoming the plant defence mechanisms (Verdejo-Lucas et al., 2009; Giné \& Sorribas, 2017; Expósito et al., 2019). Thus, other resistance sources have been assessed, including $S$. melongena lines, interspecific hybrid of $S$. integrifolium $\times S$. melongena, and the wild related species S. integrifolium, S. sisymbriifolium and S. torvum (Daunay, 2008). Nonetheless, S. torvum is currently the only wild species commercially available for use as rootstock for eggplant worldwide (Uehara et al., 2017; Öçal et al., 2018). Several S. torvum accessions and cultivars have been previously described as resistant to M. incognita (Dhivya et al., 2014), M. luci (Öçal et al., 2018), and to some populations of $M$. arenaria and M. javanica (Tzortzakakis et al., 2006; Uehara et al., 2017; Öçal et al., 2018), but 
susceptible to M. hapla (Öçal et al., 2018). Some S. torvum rootstocks have also been recently described as valuable tools for managing $M$. incognita and $M$. javanica populations from Spain, irrespective of their (a) virulence status to the resistance $N$ and $M i-1.2$ genes in pepper and tomato, respectively (García-Mendívil et al., 2019a). Nevertheless, no information has been previously reported about the effect of continuous cultivation of S. torvum on selecting for virulence and on the nematode fitness. Therefore, experiments were conducted to estimate the effect of two-year cultivation in the same plot under plastic greenhouse conditions on $M$. incognita population densities, disease severity, eggplant yield, selection for virulence and nematode fitness.

\section{Materials and methods}

\section{Experimental plots}

The experiment was conducted in a $700 \mathrm{~m}^{2}$ plastic greenhouse located at Viladecans (Barcelona, Spain). The soil texture was sandy loam with $83.8 \%$ sand, $6.7 \%$ loam and $9.5 \%$ clay, $\mathrm{pH}$ $8.7,1.8 \%$ of organic matter $(\mathrm{w} / \mathrm{w})$ and $0.5 \mathrm{dS} \mathrm{m}^{-1}$ electrical conductivity. The soil was infested in 2014 with the avirulent Mi1.2 gene isolate Agropolis from M. incognita coming from a single egg mass and multiplied in the susceptible tomato cv. Durinta (Expósito et al., 2019). The plots used in this experiment were previously cultivated with the rotation lettuce-French beaneggplant. The experiment consisted of two treatments: eggplant cv. Cristal (Semillas Fitó) grafted onto the S. torvum 'Brutus' (Semillas Fitó), and ungrafted eggplant cv. Cristal as standard for comparison. Each treatment was replicated 10 times in plots with a narrow variation in nematode densities between treatments at transplantation. Crops were grown from 16 June to 29 October 2017 (135 days) and from 20 March to 26 November 2018 (251 days) and plots maintained in black fallow between cropping seasons. Individual plots consisted of a row of $2.5 \mathrm{~m}$ with four plants spaced $0.6 \mathrm{~m}$ apart and plots within a row were spaced $1 \mathrm{~m}$ apart. Plants of each treatment were cultivated in the same plot each year to determine the effect on M. incognita population densities, the disease severity, the crop yield and the durability of the resistance. Soil of each plot was prepared individually to avoid cross contamination. Plants were irrigated as needed through a drip irrigation system and fertilized with a solution of NPK (15-5-30) at $31 \mathrm{~kg} \mathrm{ha}^{-1}$, iron chelate and micronutrients at $0.9 \mathrm{~kg} \mathrm{ha}^{-1}$. Weeds were removed manually before and during the cropping season. Fruit yield was determined weekly between 8 and 17 weeks after transplantation in 2017, and between 11 and 31 weeks in 2018. Soil temperatures and water content were recorded daily at $1 \mathrm{~h}$ intervals with digital probes 5 TM (Decagon Devices, Inc.) placed at $15 \mathrm{~cm}$ depth.

\section{Nematode population quantification}

The initial nematode population densities $(P i)$ in soil were quantified at transplantation and the final population densities $(P f)$ at the end of the crop. Soil samples were taken from each experimental plot and consisted of eight cores, taken from the first $30 \mathrm{~cm}$ of soil with an auger of diameter $2.5 \mathrm{~cm}$, that were mixed and passed through a $4 \mathrm{~mm}$ pore sieve to remove stones. The secondstage juveniles (J2) were extracted from $500 \mathrm{~cm}^{3}$ of soil, and incubated at $27 \pm 2{ }^{\circ} \mathrm{C}$ for one week, using Baermann trays
(Whitehead \& Hemming, 1965). J2 were collected using a $25 \mu \mathrm{m}$ aperture screen, counted, and expressed as J2 per $100 \mathrm{~cm}^{3}$ of soil. At the end of the crop, roots were carefully uprooted, washed, and the galling index (GI) evaluated on a scale from 0 to 10 , where $0=$ complete and healthy root system and $10=$ plants and roots dead (Zeck, 1971). The number of eggs per plant was then assessed by extracting them from roots by blender maceration in a $5 \%$ commercial bleach solution (Hussey \& Barker, 1973) and counting them. Reproduction index (RI) was calculated as the percentage of eggs produced in the rootstock compared to that in the eggplant cultivar. The response of the rootstock was categorized according to the RI as highly resistant ( $\mathrm{RI}<1 \%$ ), resistant $(1 \% \leq \mathrm{RI}<10 \%)$, moderately resistant $(10 \% \leq \mathrm{RI}<25 \%)$, slightly resistant $(25 \% \leq \mathrm{RI}<50 \%)$ or susceptible $(\mathrm{RI} \geq 50 \%)$ (Hadisoeganda \& Sasser, 1982).

\section{Selection for virulence and nematode fitness}

At the end of the plastic greenhouse experiment in 2018, two nematode subpopulations were considered according to the plant species in which they were produced, i.e. eggplant or S. torvum. The eggs extracted from roots of the ungrafted and grafted eggplants were incubated in Baermann trays at $27 \pm 2{ }^{\circ} \mathrm{C}$ to allow $\mathrm{J} 2$ emergence to determine the putative selection for virulence in a pot experiment. The $\mathrm{J} 2$ emerged in the first $24 \mathrm{~h}$ were discarded. Nematodes were collected daily for 10 days using a $25 \mu \mathrm{m}$ sieve, and stored at $9{ }^{\circ} \mathrm{C}$ until inoculation. Seeds of $S$. torvum 'Brutus' were pretreated with a $\mathrm{KNO}_{3}$ solution to improve germination (Ranil et al., 2015), transferred to vermiculite filled trays and incubated in a growth chamber at $25 \pm 2{ }^{\circ} \mathrm{C}$ and $16: 8 \mathrm{~h}$ (light:dark) photoperiod for 4 weeks. Afterwards, the seedlings were transplanted to $200 \mathrm{~cm}^{3}$ pots containing sterile sand and maintained in a growth chamber at $25 \pm 2{ }^{\circ} \mathrm{C}$ with a $16: 8 \mathrm{~h}$ (light:dark) photoperiod for 1 week, and inoculated with one J2 per $\mathrm{cm}^{3}$ sand. Each treatment was replicated 10 times. Plants were maintained in the growth chamber for 55 days, watered as needed throughout the experiment and fertilized with a slow-release fertilizer $\left(15 \% \mathrm{~N}, 9 \% \mathrm{P}_{2} \mathrm{O}_{5}, 12 \% \mathrm{~K}_{2} \mathrm{O}, 2 \% \mathrm{MgO}_{2}\right.$, microelements; Osmocote Plus). Soil temperatures were recorded daily at $30 \mathrm{~min}$ intervals with PT100 probes (Campbell Scientific Ltd).

At the end of the experiments, the roots were carefully washed, the GI evaluated, the number of egg masses and eggs per plant determined, the number of eggs per egg mass calculated as well as the RI, and the level of resistance categorized, following the procedures previously stated.

\section{Statistical analysis}

Statistical analyses were performed using R statistical software v. 3.5.1 (R Foundation for Statistical Computing). The data were not normally distributed according to the normal Shapiro-Wilk Wtest. The nonparametric analyses Mann-Whitney $U$-test was then used for paired comparisons between plant species per cropping season, between plant species per each $M$. incognita subpopulation and between $M$. incognita subpopulations per each plant species.

\section{Results}

\section{Effect of S. torvum on M. incognita reproduction, disease severity and eggplant yield}

The minimum and maximum soil temperatures during the cropping season in 2017 ranged from 21.1 to $29.9^{\circ} \mathrm{C}$, 
and from 14.6 to $31.3{ }^{\circ} \mathrm{C}$ in 2018 . The nematode population densities in soil at transplantation in 2017 ranged from 2 to $378 \mathrm{~J} 2$ per $100 \mathrm{~cm}^{3}$ of soil and did not differ $(P<0.05)$ between treatments. At the end of the crop, a higher $(P<0.05) \mathrm{GI}$, and number of $\mathrm{J} 2$ in soil and eggs per plant were registered in the ungrafted than the grafted eggplant, but fruit yield did not differ (Table 1). In 2018, the nematode population densities in soil at transplantation were between $94 \%$ and $98 \%$ less than those registered at the end of the crop in 2017 but differed $(P<0.05)$ between treatments. At the end of the crop, a higher $(P<0.05)$ GI, number of $\mathrm{J} 2$ in soil and eggs per plant were also registered in ungrafted than grafted eggplant. Grafted eggplant yielded 2.1 more kg of fruit per plant $(P<0.05)$ than ungrafted. The $S$. torvum rootstock performed as resistant $(1 \% \leq \mathrm{RI}<10 \%)$ to $M$. incognita in 2017, and highly resistant ( $\mathrm{RI}<1 \%$ ) in 2018 (Table 1).

\section{Virulence selection}

The S. torvum 'Brutus' was resistant $(1 \% \leq \mathrm{RI}<10 \%)$ to both $M$. incognita subpopulations obtained from roots of the ungrafted eggplant cv. Cristal or grafted onto the S. torvum 'Brutus' after being cultivated for two consecutive years in the same plots in a plastic greenhouse. Both M. incognita subpopulations caused between 53\% and $69 \%$ lower $(P<0.05)$ GI and produced $97 \%$ less egg masses and eggs per plant, and between $21 \%$ and $31 \%$ fewer eggs per egg mass in S. torvum than in eggplant (Table 2). The M. incognita subpopulation from roots of S. torvum 'Brutus' produced $49.4 \%$ less $(P<0.05)$ egg masses and $56 \%$ less eggs per plant in the eggplant cv. Cristal than the nematode subpopulation from roots of eggplant cv. Cristal, but these parameters did not differ between subpopulations when inoculated in S. torvum (Table 2).

\section{Discussion}

This study demonstrates for the first time that two consecutive crops of $S$. torvum in the same plots do not select for virulence in M. incognita but have an infective and reproductive fitness cost for the nematode in the susceptible eggplant. The resistance of $S$. torvum seems to

Table 1 Meloidogyne incognita population densities in soil at transplantation $(P I)$ and at the end of the crop (Pf), galling index (GI), number of eggs per plant, reproduction index (RI) and eggplant, Solanum melongena 'Cristal' yield ungrafted or grafted onto the Solanum torvum 'Brutus' rootstock cultivated from June to October 2017 (135 days) and March to November 2018 (251 days) in the same plots in a plastic greenhouse

\begin{tabular}{|c|c|c|c|c|c|c|}
\hline \multirow[b]{2}{*}{ Plant } & \multicolumn{2}{|c|}{$\mathrm{J} 2$ per $100 \mathrm{~cm}^{3}$ soil } & \multirow[b]{2}{*}{$\mathrm{Gl}$} & \multirow[b]{2}{*}{ Eggs per plant $\left(\times 10^{2}\right)$} & \multirow[b]{2}{*}{$\mathrm{Rl}(\%)$} & \multirow[b]{2}{*}{ Yield (kg per plant) } \\
\hline & $\overline{P i}$ & $P f$ & & & & \\
\hline \multicolumn{7}{|l|}{ First crop } \\
\hline Ungrafted & $51 \pm 36$ & $29054 \pm 8626$ & $4.6 \pm 0.3$ & $12323 \pm 2408$ & & $0.8 \pm 0.1$ \\
\hline Grafted & $28 \pm 12$ & $2061 \pm 818^{*}$ & $1.0 \pm 0.1^{*}$ & $228 \pm 76^{*}$ & $2.0 \pm 1.00$ & $0.8 \pm 0.1$ \\
\hline \multicolumn{7}{|l|}{ Second crop } \\
\hline Ungrafted & $686 \pm 302$ & $821 \pm 179$ & $7.5 \pm 0.2$ & $36422 \pm 5895$ & & $1.9 \pm 0.2$ \\
\hline Grafted & $127 \pm 54^{*}$ & $124 \pm 44^{*}$ & $0.9 \pm 0.1 *$ & $883 \pm 138 *$ & $0.1 \pm 0.01$ & $4.0 \pm 0.4^{*}$ \\
\hline
\end{tabular}

Data on nematode population densities in soil are the mean \pm standard error of 10 replicates. Data on GI, eggs per plant, RI and yield are the mean \pm standard error of 40 replicates.

Data followed by $*$ in the same column and year indicate significant differences $(P<0.05)$ between germplasms according to the nonparametric Mann-Whitney U-test.

Gl: galling index on a scale from 0 to 10, where $0=$ complete and healthy root system and $10=$ plant and roots dead (Zeck, 1971).

$\mathrm{RI}($ reproduction index $)=100 \times[($ number of eggs/plant in the rootstock)/(number of eggs/plant on the eggplant cv. Cristal) $]$.

Table 2 Galling index (GI), number of egg masses per plant, number of eggs per plant, reproduction index (RI) and number of eggs per egg mass of Meloidogyne incognita subpopulations obtained from roots of ungrafted eggplant, Solanum melongena 'Cristal', and grafted onto the Solanum torvum 'Brutus' rootstocks in Cristal and Brutus 55 days after cultivation in $200 \mathrm{~cm}^{3}$ pots inoculated with $1 \mathrm{~J} 2 \mathrm{~cm}^{-3}$

\begin{tabular}{|c|c|c|c|c|c|c|c|c|c|c|}
\hline \multirow[b]{2}{*}{ Plant } & \multicolumn{2}{|l|}{$\mathrm{Gl}$} & \multicolumn{2}{|c|}{$\begin{array}{l}\text { Egg masses per } \\
\text { plant }\end{array}$} & \multicolumn{2}{|l|}{ Eggs per plant } & \multicolumn{2}{|l|}{$\mathrm{RI}(\%)$} & \multicolumn{2}{|c|}{ Eggs per egg mass } \\
\hline & Ungrafted & Grafted & Ungrafted & Grafted & Ungrafted & Grafted & Ungrafted & Grafted & Ungrafted & Grafted \\
\hline Cristal & $3.8 \pm 0.2$ & $2.9 \pm 0.2^{\dagger}$ & $79 \pm 9$ & $40 \pm 3^{\dagger}$ & $39746 \pm 4392$ & $17526 \pm 2084^{\dagger}$ & & & $533 \pm 47$ & $440 \pm 27$ \\
\hline Brutus & $1.8 \pm 0.3^{*}$ & $0.9 \pm 0.2^{*, \dagger}$ & $2 \pm 1^{*}$ & $1 \pm 0 *$ & $884 \pm 230 *$ & $532 \pm 138^{*}$ & $2.2 \pm 0.6$ & $3 \pm 0.8$ & $364 \pm 55^{*}$ & $347 \pm 103^{*}$ \\
\hline
\end{tabular}

The nematode inoculum was obtained after cultivating the ungrafted and grafted eggplant cv. Cristal onto the rootstock cv. Brutus over two consecutive cropping seasons in the same plots in a plastic greenhouse.

Data are mean \pm standard error of 10 replicates. Values followed by * in the same column show significant differences $(P<0.05)$ between germplasms according to the nonparametric test Mann-Whitney U-test. Values of each parameter followed by ${ }^{\dagger}$ show significant differences $(P<0.05)$ between nematode subpopulations per each plant according to the nonparametric test Mann-Whitney U-test.

Gl: galling index on a scale from 0 to 10, where $0=$ complete and healthy root system and $10=$ plant and roots dead (Zeck, 1971).

$\mathrm{RI}($ reproduction index $)=100 \times[$ (number of eggs/plant in the rootstock)/(number of eggs/plant in the eggplant cv. Cristal) $]$. 
be more stable than other resistance genes in fruiting solanaceous crops such as tomato and pepper. In tomato, the selection for virulence to the $M i-1.2$ gene can be acquired progressively crop by crop of resistant tomato cultivars (Giné \& Sorribas, 2017) or rootstocks (Verdejo-Lucas et al., 2009), or suddenly just after one tomato crop grafted onto the resistant rootstock cv. Aligator (Expósito et al., 2019). Regarding pepper, the selection for virulence to the $\mathrm{Me} 3$ gene has been reported after two consecutive pepper crops grafted onto the rootstock cv. Atlante (Ros-Ibáñez et al., 2014). In relation to the $N$ gene, virulence has been reported in the USA but without any information on the selection process (Thies, 2011). Yang et al. (2014) consider that the entire disease resistance pathway is amplified in S. torvum compared with tomato and potato, enhancing plant defence mechanisms and resistance durability.

The acquisition of virulence to a resistance gene can have a fitness cost for the nematode in susceptible cultivars of the same plant species (Castagnone-Sereno et al., 2007; Djian-Caporalino et al., 2011; Expósito et al., 2019) after a minimum number of exposures to this resistance gene. For example, three resistant tomato crops were needed to affect the infectivity, reproduction and fecundity of a partially virulent $M$. incognita subpopulation in susceptible tomato compared to the avirulent subpopulation (Expósito et al., 2019). Surprisingly, the results of the present study revealed that the infective and reproductive fitness of the nematode decreased without having been selected for virulence after two years of repeated cultivation. The causes for this loss of fitness as well as the stability of this characteristic should be investigated. In a nematode field population, a certain proportion of infective $\mathrm{J} 2$ can counteract the S. torvum resistance in a proportion that is maintained in the offspring, irrespective of the plant resistance status in which they were originated, as observed in the experiment here. Nonetheless, the proportion of the offspring originated in S. torvum has a fitness cost manifested in susceptible eggplant. This finding can have important consequences for managing $M$. incognita by agronomic methods because the nematode reproduction in susceptible eggplant decreased by about $56 \%$. Therefore, the use of different resistant sources in rotation with susceptible ones will decrease the risk of selecting virulent nematode populations. Solanaceae and Cucurbitaceae are the two most common botanical families used in rotation under protected cultivation (Moncada et al., 2013). In addition to the commercially available resistant tomato, pepper and eggplant cultivars and/or rootstocks, some other resistance sources in the Cucurbitaceae family such as $\mathrm{Cucu}$ mis metuliferus and Citrullus amarus could be used as rootstocks in rotation schemes. Moreover, the resistance of C. metuliferus, C. amarus and S. torvum is also expressed against virulent populations to the $M i-1.2$ and $N$ resistance genes (Expósito et al., 2018; GarcíaMendívil et al., 2019b). Plant resistance is an effective and economically profitable control method (Sorribas et al., 2005) that can be durable if it is used in a proper manner (Djian-Caporalino et al., 2011). Among the proposed strategies to increase resistance durability, alternating only two resistance genes reduces virulence selection but does not prevent it (Expósito et al., 2019). Including more resistance sources, some of them having a fitness cost for the nematode such as that in S. torvum, could prevent the selection for virulence to specific resistance genes and could also reduce the infective and reproductive capability of the nematode in susceptible germplasm.

In relation to crop yield, significant differences between ungrafted and grafted eggplant were only detected after long cropping periods. An eggplant yield increase of $27 \%$ was recorded when cultivated over 9 months, but no differences were found for cropping periods shorter than 6.5 months (Çürük et al., 2009; Gisbert et al., 2011; Moncada et al., 2013; Sabatino et al., 2013; Bogoescu \& Doltu, 2015). In the present study, grafted eggplant yielded a $110 \%$ more than the ungrafted when cropped over 8.3 months, but did not differ when cultivated over 4.5 months.

In summary, grafted eggplant onto $S$. torvum can yield significantly more in nematode-infested soil depending on $P i$ and/or crop duration and is a valuable tool for managing the three tropical Meloidogyne spp. irrespective of its (a)virulence status to other resistance genes in fruiting solanaceous crops; it reduces the infective and reproductive fitness of the nematode in susceptible eggplant after two consecutive crops without selecting for nematode virulence. However, special attention should be given in relation to variants of the nematode able to overcome resistance in $S$. torvum. Recently, the genotype A2-J of M. arenaria from Japan has been reported as virulent to S. torvum, but not the A2-O. Interestingly, the distribution area of the genotype A2-J overlaps with the cultivation area of eggplant (Uehara et al., 2017). Additional long-term studies will be necessary to determine the resistance durability.

\section{Acknowledgements}

The authors thank MINECO and FEDER for funding projects AGL2013-49040-C2-1-R and AGL2017-89785$\mathrm{R}$, and CONACYT for providing $\mathrm{PhD}$ funding to $\mathrm{H}$. A. García-Mendívil. Thank are also given to Laura Mateo from Semillas Fitó for providing seeds of S. torvum cv. Brutus, and to Sergi García, Alejandro Expósito and Miquel Masip for technical assistance. The authors have no conflict of interest to declare.

\section{References}

Araujo MT, Bassett MJ, Augustine JJ, Dickson DW, 1982. Effects of the temperature and duration of the initial incubation period on resistance to Meloidogyne incognita in tomato. Journal of Nematology 14, 411-3.

Bogoescu M, Doltu M, 2015. Effect of grafting eggplant (Solanum melongena L.) on its selected useful characters. Bulletin of the University of Agricultural Sciences \& Veterinary Medicine ClujNapoca. Horticulture 72, 318-26.

Castagnone-Sereno P, Bongiovanni M, Wajnberg E, 2007. Selection and parasite evolution: a reproductive fitness cost associated with virulence 
in the parthenogenetic nematode Meloidogyne incognita. Evolutionary Ecology 21, 259-70.

Cortada L, Sorribas FJ, Ornat C, Kaloshian I, Verdejo-Lucas S, 2008. Variability in infection and reproduction of Meloidogyne javanica on tomato rootstocks with the Mi resistance gene. Plant Pathology 57, 1125-35.

Çürük S, Dasgan HY, Mansuroğlu S, et al., 2009. Grafted eggplant yield, quality and growth in infested soil with Verticillium dabliae and Meloidogyne incognita. Pesquisa Agropecuária Brasileira 44, 1673-81.

Daunay MC. 2008. Eggplant. In: Prophens J, Nuez F, eds. Vegetables II. Handbook of Plant Breeding, Vol. 2. New York, NY, USA: Springer, 163-220.

Dhivya R, Sadasakthi A, Sivakumar M, 2014. Response of wild solanum rootstocks to root-knot nematode (Meloidogyne incognita Kofoid and White). International Journal of Plant Sciences (Muzaffarnagar) 9, 117-22.

Djian-Caporalino C, Molinari S, Palloix A, et al., 2011. The reproductive potential of the root-knot nematode Meloidogyne incognita is affected by selection for virulence against major resistance genes from tomato and pepper. European Journal of Plant Pathology $131,431-40$

Expósito A, Munera M, Giné A, et al., 2018. Cucumis metuliferus is resistant to root-knot nematode Mi1.2 gene (a) virulent isolates and a promising melon rootstock. Plant Pathology 67, 1161-7.

Expósito A, García S, Giné A, Escudero N, Sorribas FJ, 2019. Cucumis metuliferus reduces Meloidogyne incognita virulence against the Mi1.2 resistance gene in a tomato-melon rotation sequence. Pest Management Science 75, 1902-10.

FAOSTAT, 2017. Food and agriculture data. Food and Agriculture Organization of the United Nations. Statistics Division. [www.fao. org/faostat/]. Accessed in 1 April 2019.

García-Mendívil HA, Escudero N, Sorribas FJ, 2019a. Host suitability of Solanum torvum cultivars to Meloidogyne incognita and $M$. javanica and population dynamics. Plant Pathology 68, 1215-24.

García-Mendívil HA, Munera M, Giné A, et al., 2019b. Response of two Citrullus amarus accessions to isolates of three species of Meloidogyne and their graft compatibility with watermelon. Crop Protection 119, 208-13.

Giné A, Sorribas FJ, 2017. Quantitative approach for the early detection of selection for virulence of Meloidogyne incognita on resistant tomato in plastic greenhouses. Plant Pathology 66, 1338-44.

Gisbert C, Prohens J, Raigón MD, Stommel JR, Nuez F, 2011. Eggplant relatives as sources of variation for developing new rootstocks: Effects of grafting on eggplant yield and fruit apparent quality and composition. Scientia Horticulturae 128, 14-22.

Greco N, Di Vito M, 2009. Population dynamics and damage level. In: Perry RN, Moens M, Starr JL, eds. Root-knot Nematodes. Wallingford, UK: CAB International, 246-74.

Hadisoeganda WW, Sasser JN, 1982. Resistance of tomato, bean, southern pea, and garden pea cultivars to root-knot nematodes based on host suitability. Plant Disease 66, 145-50.

Hallman J, Meressa BH, 2018. Nematode parasites of vegetables. In: Sikora RA, Coyne D, Hallmann J, Timper P, eds. Plant parasitic nematodes in subtropical and tropical agriculture. Wallingford, UK: CAB International, 346-410.

Hussey RS, Barker K, 1973. A comparison of methods of collecting inocula of Meloidogyne spp., including a new technique. Plant Disease Reporter 57, 1025-8.
Lee JM, Oda M, 2002. Grafting of herbaceous vegetable and ornamental crops. Horticultural Reviews 28, 61-124.

Moncada A, Miceli A, Vetrano F, Mineo V, Planeta D, D'Anna F, 2013. Effect of grafting on yield and quality of eggplant (Solanum melongena L.). Scientia Horticulturae 149, 108-14.

Nyczepir AP, Thomas SH, 2009. Current and future management strategies in intensive crop production systems. In: Perry RN, Moens M, Starr JL, eds. Root-knot Nematodes. Wallingford, UK: CAB International, 412-43.

Öçal S, Özalp T, Devran Z, 2018. Reaction of wild eggplant Solanum torvum to different species of root-knot nematodes from Turkey. Journal of Plant Diseases and Protection 125, 577-80.

Ranil RHG, Niran HL, Plazas M, et al., 2015. Improving seed germination of the eggplant rootstock Solanum torvum by testing multiple factors using an orthogonal array design. Scientia Horticulturae 193, 174-81.

Roberts PA, 2002. Concepts and consequences of resistance. In: Starr JL, Cook R, Bridge J, eds. Plant Resistance to Parasitic Nematodes. Wallingford, UK: CAB International, 23-41.

Ros-Ibáñez C, Robertson L, Martínez-Lluch M, Cano-García A, LacasaPlasencia A, 2014. Development of virulence to Meloidogyne incognita on resistant pepper rootstocks. Spanish Journal of Agricultural Research 12, 225-32.

Sabatino L, Palazzolo E, D’Anna F, 2013. Grafting suitability of Sicilian eggplant ecotypes onto Solanum torvum: Fruit composition, production and phenology. Journal of Food, Agriculture \& Environment 11, 1195-200.

Sorribas FJ, Ornat C, Verdejo-Lucas S, Galeano M, Valero J, 2005. Effectiveness and profitability of the Mi-resistant tomatoes to control root-knot nematodes. European Journal of Plant Pathology 111, 2938.

Thies JA, 2011. Virulence of Meloidogyne incognita to expression of $N$ gene in pepper. Journal of Nematology 43, 90.

Thies JA, Buckner S, Horry M, Hassell R, Levi A, 2015. Influence of Citrullus lanatus var. citroides rootstocks and their F1 hybrids on yield and response to root-knot nematode, Meloidogyne incognita, in grafted watermelon. HortScience 50, 9-12.

Tzortzakakis EA, Bletsos FA, Avgelis AD, 2006. Evaluation of Solanum rootstock accessions for control of root-knot nematodes and tobamoviruses. Journal of Plant Diseases and Protection 113, 188-9.

Uehara T, Tateishi Y, Kadota Y, Iwahori H, 2017. Differences in parasitism of Meloidogyne incognita and two genotypes of M. arenaria on Solanum torvum in Japan. Journal of Phytopathology $165,575-9$.

Verdejo-Lucas S, Cortada L, Sorribas FJ, Ornat C, 2009. Selection of virulent populations of Meloidogyne javanica by repeated cultivation of $\mathrm{Mi}$ resistance gene tomato rootstocks under field conditions. Plant Pathology 58, 990-8.

Whitehead AG, Hemming JR, 1965. A comparison of some quantitative methods of extracting small vermiform nematodes from soil. Annals of Applied Biology 55, 25-38.

Yang X, Cheng YF, Deng C, et al., 2014. Comparative transcriptome analysis of eggplant (Solanum melongena L.) and turkey berry (Solanum torvum Sw.): phylogenomics and disease resistance analysis. BMC Genomics 15, 412.

Zeck WM, 1971. Rating scheme for field evaluation of root-knot nematode infestations. Pflanzenschutz Nachrichten Bayer 24, 141-4. 